\title{
Diastolic function after cardiac and heart-lung transplantation
}

\author{
GERD HAUSDORF, * NICHOLAS R BANNER, ANDREW MITCHELL, \\ ASHGAR KHAGHANI, MARINA MARTIN, MAGDI YACOUB
}

From Harefield Hospital, Harefield, Middlesex, and the ${ }^{\star}$ University of Hamburg, Federal Republic of Germany

SUMMARY The mechanical efficiency of left ventricular contraction and relaxation, the asynchrony of the onset of left ventricular relaxation, the time constant of left ventricular isovolumic pressure decay, and left ventricular chamber and myocardial stiffness were analysed in 32 patients after cardiac (24) and heart-lung transplantation (8). After cardiac transplantation left ventricular myocardial stiffness was increased and a mild degree of incoordinate contraction and relaxation was seen. In contrast, after heart-lung transplantation diastolic function was almost normal. Impairment of passive diastolic properties was significantly related to the ischaemic time of the donor heart and the donor's age. The index of left ventricular asynchrony was related to the ischaemic time and the recipient's age. The interval between transplantation and study did not influence the number of rejection episodes.

This study confirms the presence of diastolic dysfunction after cardiac transplantation. Impairment of diastolic function seems to be related to the ischaemic time of the donor heart and to a mismatch between the size of the donor heart and the recipient's needs.

Cardiac transplantation and heart-lung transplantation have become an accepted treatment for end stage cardiac and cardiopulmonary disease. ${ }^{1-6}$ The exercise capacity of transplant recipients is good, but less than that of normal subjects. ${ }^{7-10}$ Its contractile state and contractile reserve have also been shown to be normal. ${ }^{11} 12$ In contrast with systolic function there is increasing evidence of impaired diastolic function after cardiac transplantation. ${ }^{13-15}$

We have analysed the diastolic function in the transplanted heart. Three major components of diastole were analysed: synchrony of left ventricular relaxation, ${ }^{16-19}$ duration of left ventricular relaxation, ${ }^{20-23}$ and left ventricular passive diastolic properties. ${ }^{24-27}$ Furthermore, the relation between certain variables such as ischaemic time of the donor heart, ${ }^{28-30}$ number of rejection episodes, type of immunosuppression, ${ }^{31-32}$ and diastolic function were studied.

Requests for reprints to Professor Magdi Yacoub, Harefield Hospital, Harefield, Middlesex UB9 6JH.

Accepted for publication 14 February 1989

\section{Patients and methods}

All studies were performed during routine yearly follow up cardiac catheterisations after cardiac or heart-lung transplantation.

\section{PATIENTS}

Thirty two transplanted patients were studied. Twenty four patients underwent cardiac transplantation and eight patients heart-lung transplantation. Preoperative diagnosis before cardiac transplantation was cardiomyopathy in 16 patients and ischaemic heart disease in eight patients. The heartlung transplantation group was made up of five patients with primary pulmonary hypertension, two patients with Eisenmenger's syndrome caused by congenital heart disease, and one patient with cystic fibrosis. Immunosuppression consisted of treatment with cyclosporin and azathioprine in 23 transplanted patients, ${ }^{33}$ steroids and azathioprine in four patients with transplants, and all three drugs (cyclosporin, steroids, and azathioprine) in two patients with transplants. Two patients were treated with cyclosporin alone and one with azathioprine alone, so only 
five patients were not treated with cyclosporin. All other medications were stopped 24 hours before the study. None of the patients received drugs likely to alter diastolic function (such as $\beta$ blockers or calcium antagonists). Tables 1-3 give patient data.

\section{CONTROL GROUPS}

Patients with transplants were compared with controls with normal cardiac anatomy and left ventricular function. Three control groups (control groups 1 a to c) were used because it was impossible to perform all measurements of diastolic function in each of the controls. The control groups consisted of individuals who had diagnostic cardiac catheterisation for atypical chest pain or suspected congenital heart disease. All were in sinus rhythm and were found to have angiographically normal coronary arteries and structurally normal hearts. There were 12 in control group 1a from which normal values for the time constant of isovolumic pressure decay and cycle efficiency were obtained. Control group 1b consisted of 20 normal individuals from whom left ventricular angiograms were obtained by the same techniques as in the patients with transplants. From this control group we obtained normal values for the evaluation of left ventricular asynchrony. Control group 1c consisted of 10 normal individuals from whom we obtained normal values for passive diastolic properties.

\section{METHODS}

\section{Cardiac catheterisation}

In all patients with transplants coronary angiograms were performed and multiple (usually three) endomyocardial right ventricular biopsy specimens were obtained from the femoral approach. None of the patients showed cardiac allograft rejection accor-

Table 1 Patient data

\begin{tabular}{|c|c|c|c|}
\hline & $\begin{array}{c}\text { Total } \\
\text { group } \\
(\text { no) }\end{array}$ & $\begin{array}{l}\text { Cardiac } \\
\text { transplants } \\
\text { (no) }\end{array}$ & $\begin{array}{l}\text { Heart-lung } \\
\text { transplants } \\
(\text { no })\end{array}$ \\
\hline $\begin{array}{c}\text { Recipient } \\
<18 \\
18-30 \\
31-40 \\
41-51 \\
>51\end{array}$ & $\begin{array}{r}6 \\
9 \\
2 \\
11 \\
4\end{array}$ & $\begin{array}{r}3 \\
5 \\
1 \\
11 \\
4\end{array}$ & $\begin{array}{l}3 \\
4 \\
1 \\
- \\
-\end{array}$ \\
\hline $\begin{array}{c}\text { Donor ag } \\
<16 \\
16-20 \\
21-25 \\
26-30 \\
>30\end{array}$ & $\begin{array}{r}10 \\
10 \\
8 \\
3 \\
1\end{array}$ & $\begin{array}{l}6 \\
9 \\
6 \\
2 \\
1\end{array}$ & $\begin{array}{l}4 \\
1 \\
2 \\
1 \\
\end{array}$ \\
\hline $\begin{array}{c}\text { Time sin } \\
1 \\
2 \\
3 \\
>3\end{array}$ & $\begin{array}{c}\text { tion }(y \\
15 \\
9 \\
5 \\
3\end{array}$ & $\begin{array}{l}8 \\
8 \\
5 \\
3\end{array}$ & $\begin{array}{l}7 \\
1 \\
- \\
\end{array}$ \\
\hline
\end{tabular}

Table 2 Interval between (N)ss clamping of the aorta in the donor and reperfusion in the recipient

\begin{tabular}{llll}
\hline $\begin{array}{l}\text { Ischaemic time } \\
\text { (h) }\end{array}$ & $\begin{array}{l}\text { Total } \\
\text { group } \\
\text { (no) }\end{array}$ & $\begin{array}{l}\text { Cardiac } \\
\text { transplants } \\
\text { (no) }\end{array}$ & $\begin{array}{l}\text { Heart-lung } \\
\text { transplants } \\
\text { (no) }\end{array}$ \\
\hline$<1$ & 1 & - & 1 \\
$1.0-1.5$ & 3 & 3 & - \\
$1.5-2 \cdot 0$ & 6 & 4 & 2 \\
$2 \cdot 0-2.5$ & 7 & 5 & 2 \\
$2.5-3.0$ & 6 & 4 & 2 \\
$3.0-3.5$ & 4 & 3 & 1 \\
$3.5-4.0$ & 4 & 4 & \\
$>4.0$ & 1 & 1 & \\
\hline
\end{tabular}

ding to criteria defined by Billingham and Griffith $e t$ al..$^{335}$ No attempt was made to quantify myocardial fibrosis, as this might have been influenced by the presence of scar tissue from previous biopsies.

Angiograms and endomyocardial biopsies were postponed until the measurements for the evaluation of relaxation, cycle efficiency, and passive diastolic filling were completed. High fidelity left ventricular pressure recordings were obtained with micromanometer-tipped 4F fibreoptic catheters (Camino Laboratories, model 110-4). The high fidelity catheters were balanced and electronically calibrated immediately before insertion and after withdrawal. No significant baseline shift occurred during the recording period.

Time constant of isovolumic pressure decay

For calculation of the time constant of isovolumic pressure decay left ventricular pressure tracings (paper speed $200 \mathrm{~mm} / \mathrm{s}$ ) were manually digitised with an electronic digitiser. The first derivative of the left ventricular pressure curve $(\mathrm{dP} / \mathrm{dt})$ was obtained by digital differentiation with a Cardio 200 computer (Kontron Image Analysis). For calculation of the time constant of isovolumic pressure decay the isovolumic relaxation period was defined as the interval between the minimum value for the first derivative of the left ventricular pressure $\left(\mathrm{dP} / \mathrm{dt}_{\min }\right)$ and the time when the pressure returned to the end diastolic pressure (LVEDP) of the preceding cardiac cycle. ${ }^{160-23} \mathrm{~A}$ monoexponential model with asymp-

Table 3 Increased number of rejection episodes *

\begin{tabular}{llll}
\hline & $\begin{array}{l}\text { Total } \\
\text { group }\end{array}$ & $\begin{array}{l}\text { Cardiac } \\
\text { transplants }\end{array}$ & $\begin{array}{l}\text { Heart-lung } \\
\text { transplants }\end{array}$ \\
\hline First 3 months & 9 of 32 & 7 of 24 & 2 of 8 \\
3 months to 1 year & 5 of 32 & 4 of 24 & 1 of 8 \\
2nd year & 4 of 14 & 4 of 13 & None \\
$>$ 2nd year & None & None & None \\
\hline
\end{tabular}

Histological grading of rejection..$^{34}$

*Three rejection episodes during the first three months after transplantation, two rejection episodes during the subsequent nine months, and one rejection episode yearly thereafter were arbitrarily defined as "normal"; the table gives the number of rejection episodes beyond these normal estimates. 
tote was used to calculate the time constant of isovolumic pressure decay $T: P(t)=a \star e^{b \star t}+C$, where $P(t)$ is instantaneous $L V$ pressure; $t$ is time; a and $\mathrm{b}$ are constants; and $\mathrm{C}$ is the asymptote. The time constant $T$ of isovolumic pressure decay is defined as: $\mathrm{T}=-1 / \mathrm{b}$, where $\mathrm{T}$ was calculated by iteration by the least squares method (best fit).

\section{Echocardiograms}

$M$ mode echocardiograms of the left ventricle were recorded in patients in the supine position at the tip of the mitral valve leaflets with a $3.5 \mathrm{MHz}$ or 2.25 $\mathrm{MHz}$ transducer and an Ekoline 20A echocardiograph (Smith-Kline Instruments). Left ventricular pressure was recorded simultaneously as mentioned above. The recordings were made at a paper speed of at least $100 \mathrm{~mm} / \mathrm{s}$.

\section{Cycle efficiency}

Pressure-dimension loops were constructed from the left ventricular internal dimension and the instantaneous left ventricular pressure as originally described by Gibson and Brown. ${ }^{1718}$ Cycle efficiency was defined as the ratio of the area within the pressuredimension loop and that of the rectangle that encloses it. ${ }^{17} 18$

\section{Assessment of left ventricular asynchrony}

Left ventricular asynchrony was assessed through frame by frame analysis of left ventricular angiograms. ${ }^{16}$ No extrasystoles or postextrasystoles were analysed. Left ventricular angiograms were performed in the right anterior oblique position at a frame rate of 50 frames/s after pressure recordings and echocardiograms were completed.

Frame by frame analysis of regional wall motion was performed from the digitised ventriculograms by a Cardio 200 computer (Kontron Image Analysis). Regional wall motion was analysed by a polar coordinate system with 24 segments (fig 1). No superposition was performed (fixed reference system). Regions adjacent to the mitral valve were excluded from analysis. Regional changes in area were calculated for each segment frame by frame. The delay between minimum cavity dimension and minimal segment area was calculated for each segment and the standard deviation of these intervals was defined as the "index of left ventricular asynchrony."

\section{Evaluation of left ventricular passive diastolic properties}

Passive viscoelastic diastolic properties were evaluated by simultaneous recording of the $M$ mode echocardiograms and left ventricular diastolic pressure. From the digitised $M$ mode echocardiograms the instantaneous internal left ventricular dimension
$\left(D_{i}(t)\right)$, posterior wall thickness $(h(t))$, midwall left ventricular circumference $(l(t))$, and the first derivative of the midwall left ventricular circumference (dl/dt) were obtained. The circular shape of the left ventricular short axis was confirmed by cross dimensional echocardiography. For the calculation of chamber stiffiness and myocardial stiffness the time interval between minimum diastolic pressure and end diastolic pressure was analysed. Passive diastolic properties were analysed at end expiration. The stiffiness of the left ventricular chamber and myocardium was calculated according to the method described by Hess et al $^{27}$ (appendix A).

\section{STATISTICAL ANALYSIS}

We used Student's $t$ test for unpaired data to compare patients with transplants and controls. Simple, partial, and multiple regressions were used to analyse the influence of specific variables such as ischaemic time and donor age on diastolic function. A $p$ value of $<0.05$ was regarded as statistically significant.

\section{Results}

\section{STANDARD HAEMODYNAMIC DATA}

Table 4 shows the standard haemodynamic data obtained during diagnostic cardiac catheterisation in patients with transplants and in controls. The heart rate was significantly lower in control group $1 \mathrm{c}(\mathrm{p}<$ 0.001 ) than in the patients with transplants. Left ventricular systolic and end diastolic pressure, end diastolic volume, and ejection fraction did not differ between the groups.

\section{CYCLE EFFICIENCY}

Although cycle efficiency was slightly lower in the patients with transplants, there was no significant difference compared with the control group (table 5). Cycle efficiency was significantly greater after heartlung transplantation than after cardiac transplantation ( $p<0.05)$. After cardiac transplantation cycle efficiency was slightly less than in controls $(p<0.05)$ (table 5).

Regression analysis showed a significant inverse relation between recipient age and cycle efficiency in all patients with transplants $(r=-0.457 ; p<0.01)$. No significant correlation between recipient age and cycle efficiency could be shown in the cardiac transplant group $(r=-0.327$; NS).

\section{INDEX OF LEFT VENTRICULAR ASYNCHRONY}

No difference in the synchrony of the onset of relaxation was noted between any of the groups (table 5). Asynchronous onset of relaxation was seen in only two cardiac transplant patients (fig 2). We saw no 

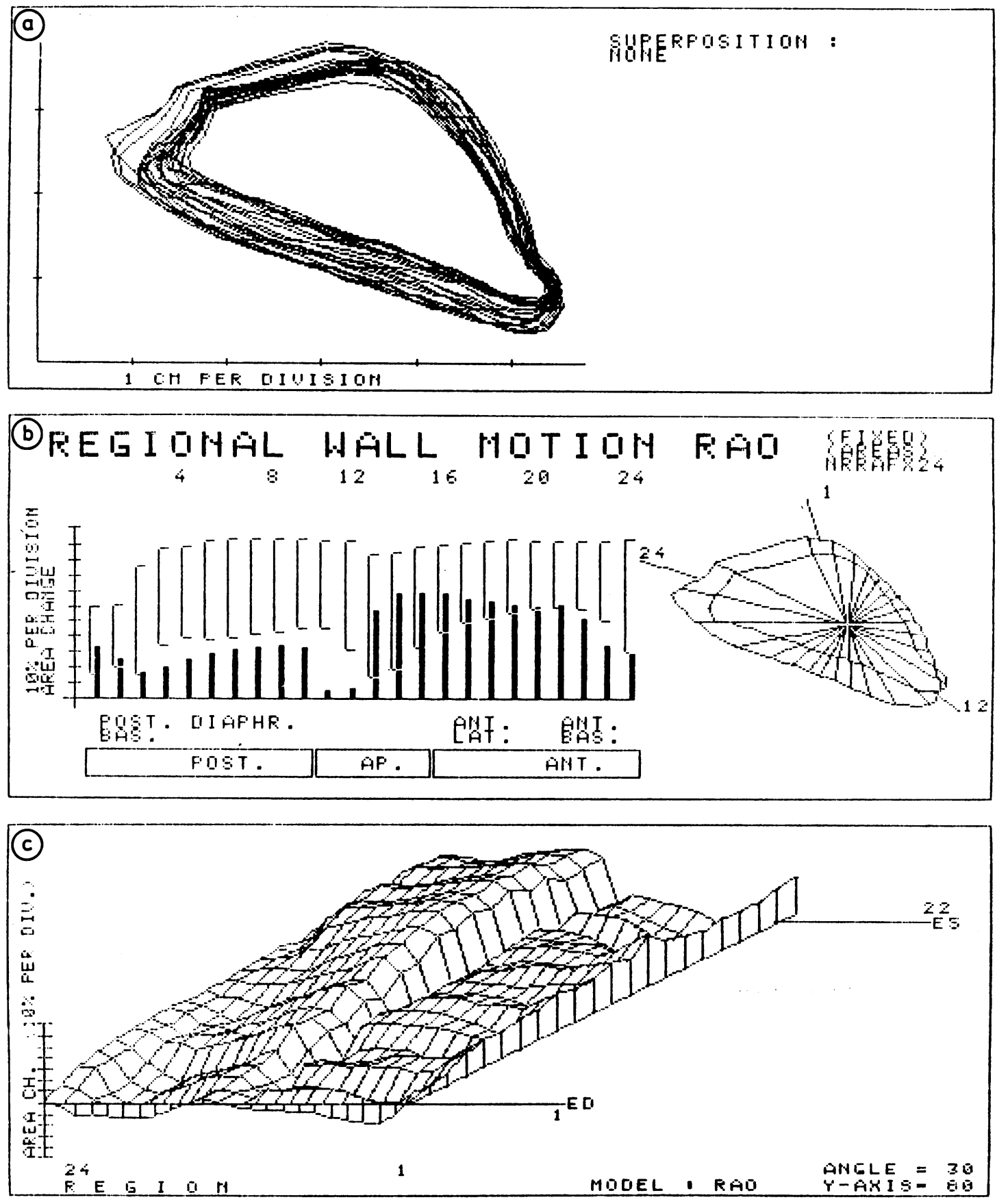

Fig 1 Assessment of left ventricular asynchrony after cardiac and combined heart and lung transplantation. (a) Regional wall motion was analysed from left ventricular contours digitised frame by frame by (b) a polar coordinate system with 24 segments without superposition (fixed reference system). The delay between minimum cavity dimension and minimal segment area was calculated for each segment and the standard deviation of these time intervals was defined as the index of left ventricular asynchrony ${ }^{16}$ The three dimensional display shows the percentage area change ( $z$ axis) for each frame (y axis) and segment ( $x$ axis) graphically. 
Table 4 Standard haemodynamic variables (mean (SD))

\begin{tabular}{lccc}
\hline & $\begin{array}{c}\text { Total } \\
\text { group }\end{array}$ & $\begin{array}{l}\text { Cardiac } \\
\text { transplants }\end{array}$ & $\begin{array}{c}\text { Heart-lung } \\
\text { transplants }\end{array}$ \\
\hline No & 32 & 24 & 8 \\
HR & $89(13)$ & $86(10)$ & $97(8) \star \star$ \\
EF & $68(9)$ & $68(9)$ & $69(7)$ \\
LVSP & $122(15)$ & $121(12)$ & $126(14)$ \\
LVEDP & $10(4)$ & $10(4)$ & $10(3)$ \\
LVEDVI & $80(7)$ & $82(6)$ & $74(9)$ \\
& Control & Control & Control \\
& group 1a & group 1b & group 1c \\
No & 12 & 20 & 10 \\
HR & $83(9) \star$ & $85(7) \star \star$ & $71(4) \star \star \star$ \\
EF & $71(4)$ & $71(5)$ & $69(2)$ \\
LVSP & $128(11)$ & $124(7)$ & $117(3)$ \\
LVEDP & $7(3)$ & $7(3)$ & $8(1)$ \\
LVEDVI & $81(9)$ & $83(7)$ & $85(7)$ \\
\hline
\end{tabular}

HR, heart rate; EF, left ventricular ejection fraction; LVSP, left ventricular peak systolic pressure; LVEDP, left ventricular end diastolic pressure; LVEDVI, left ventricular end diastolic volume index.

Heart-lung transplantation group $v$ control group $1 \mathrm{a},{ }^{\star} \mathrm{p}<0.05$; $v$ control group $1 \mathrm{~b}, \star^{\star} \mathrm{p}<0.01$; and $v$ control group $1 \mathrm{c}$, $\star \star \star p p<0.001$. Control group 1c $v$ patient groups, $\star \star \star \mathrm{p} p<0.001$.

Pressure measurements were performed with fluid flled catheters during diagnostic cardiac catheterisation.

differences between those patients who underwent cardiac transplantation and those who underwent heart-lung transplantation.

Regression analysis showed a modest influence of the ischaemic time and recipient age on the index of left ventricular asynchrony (multiple correlation: $r=$ 0.399; $\mathrm{p}<0.05)$. Simple correlations were not significant (recipient age $v$ index of asynchrony, $r=$ $0 \cdot 164$; ischaemic time $v$ index of asynchrony, $r=$ $0 \cdot 317$ ).

\section{TIME CONSTANT OF ISOVOLUMIC PRESSURE}

$\operatorname{DECAY}(\mathrm{T})$

$T$ was normal in patients with transplants (table 5 , fig 2); it was significantly prolonged in only two patients with transplants.

\section{LEFT VENTRICULAR CHAMBER STIFFNESS}

Although the constant of left ventricular chamber stiffness $b_{c}$ (see appendix $A$ ) was increased in seven of the patients with transplants (fig 3 ), mean values for

Table 5 Cycle efficiency, index of left ventricular asynchrony, and time constant of isovolumic pressure decay after cardiac and heart-lung transplantation (mean (SD))

\begin{tabular}{|c|c|c|c|}
\hline & $\begin{array}{l}\text { Cycle } \\
\text { efficiency } \\
(\%)\end{array}$ & $\begin{array}{l}\text { Index of } \\
\text { asynchrony } \\
\text { (ms) }\end{array}$ & $\begin{array}{l}T \\
(m s)\end{array}$ \\
\hline $\begin{array}{l}\text { Total group (32) } \\
\text { Cardiac (24) } \\
\text { Heart-lung (8) } \\
\text { Control group }\end{array}$ & $\begin{array}{l}77 \cdot 8(8.9) \\
75.9(9 \cdot 4)^{\star} \\
83.6(3.4)^{\star \star} \\
82.1(5 \cdot 1)\end{array}$ & $\begin{array}{l}25 \cdot 8(12) \\
26.5(8 \cdot 7) \\
24.5(8 \cdot 6) \\
23.6(9.5)\end{array}$ & $\begin{array}{l}44 \cdot 3(11 \cdot 2) \\
45 \cdot 3(9 \cdot 1) \\
41 \cdot 6(8 \cdot 7) \\
47 \cdot 1(12 \cdot 9)\end{array}$ \\
\hline
\end{tabular}

*Cardiac transplants $v$ control group, $p<0.05$; ${ }^{\star \star}$ cardiac transplants $v$ heart-lung transplants, $p<0.05$. patients with transplants and controls did not differ significantly (table 6; fig 3). In addition, the elastic constant $a_{c}$ of the pressure-circumference relation and the constant of left ventricular chamber viscosity $v_{C}$ were similar in both groups (table 6). Figure 4 shows the "averaged" pressure-circumference and stress-strain curves.

Regression analysis showed a significant influence of ischaemic time $(r=0.410 ; p<0.05)$ and donor age $(r=-0.381 ; p<0.05)$ on the constant of left ventricular chamber stiffness $b_{c}$ (multiple correlation $r=0.530 ; p<0.003$ ). An influence of donor age on $b_{c}$ could also be shown in cardiac transplant patients $(r=-0.404 ; p<0.05)$.

\section{LEFT VENTRICULAR MYOCARDIAL STIFFNESS}

The reference midwall circumference $\mathrm{L} 1$ was identical in controls and those with transplants (table 6). Both the constant of left ventricular myocardial stiffness $b_{M}(p<0.02)$ and the elastic constant $a_{M}$ $(p<0.002)$ of the stress-strain relation were significantly increased in patients with transplants (table 6 ). The constants $a_{M}$ and $b_{M}$ were increased particularly after cardiac transplantation $(p<0.001$ and $p<0.01$, respectively). These indices were not significantly increased after heart-lung transplantation (table 6, fig 3). Myocardial stiffness $b_{M}$ was increased in only one heart-lung transplant (fig 3); this, however, increased the standard deviation substantially so that no significant difference between the two patient groups could be shown. The constant of left ventricular myocardial viscosity $\left(v_{M}\right)$ was similar in all groups.

As with chamber stiffness, regression analyses
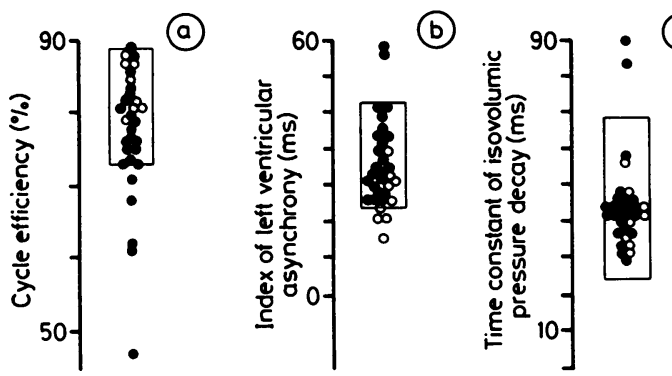

Fig 2 Individual data and corresponding normal ranges (mean (SD) for cycle efficiency, index of left ventricular asynchrony, and time constant of left ventricular pressure decay. Solid circles indicate cardiac transplant patients, open circles indicate heart-lung transplant patients. Cycle efficiency was significantly reduced after cardiac transplantation $(p<0.05)$, while it was normal after heartlung transplantation. The index of left ventricular asynchrony and the time constant of left ventricular pressure decay were normal after cardiac and heart-lung transplantation. 


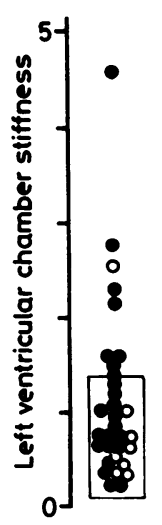

(a)



Fig 3 Individual data and corresponding normal ranges (mean $(S D)$ ) of left ventricular chamber stiffness $\left(b_{c}\right)(a)$ and left ventricular myocardial stiffness $\left(b_{M}\right)(b)$ are shown. Solid circles are patients after cardiac transplantation and open circles indicate patients after combined heart and lung transplantation. The constant of left ventricular myocardial stiffness $b_{M}$ was significantly increased in the whole group $(p<0.02)$ and especially after cardiac transplantation $(p<0.01)$, while the constant of left ventricular chamber stiffness $b_{c}$ did not differ significantly from the control group. After heart-lung transplantation only one patient showed an increased chamber and myocardial stiffness.

showed a significant correlation between the constant of left ventricular myocardial stiffness $b_{M}$ and both ischaemic time and donor age (multiple correlation $r=0.402 ; p<0.05)$. Simple correlations were not significant (ischaemic time $v$ constant of myocardial stiffness $b_{M}: r=0.196$; donor age $v$ constant of myocardial stiffness $b_{M}: r=-0.326$ ).

\section{CORONARY ANGIOGRAMS}

Yearly follow up coronary angiograms showed normal coronary arteries in 24 patients with transplants, mild atherosclerotic plaques in six patients with
Hausdorf, Banner, Mitchell, Khaghani, Martin, Yacoub transplants, and slight $(<30 \%)$ coronary stenoses in two patients with transplants. Significant coronary stenoses were not seen in any of the patients studied.

ENDOMYOCARDIAL BIOPSIES

Endomyocardial biopsy specimens showed no evidence of cardiac allograft rejection in any of the patients with transplants.

\section{Discussion}

Although a transplanted heart comes from a young donor without evidence of preexisting cardiovascular disease, its later function could be influenced by the $N$ brain death of the donor, ${ }^{30}$ as well as by impaired +0 haemodynamic function and cardiovascular disease $\vec{N}$ of the donor. ${ }^{28} 29$ Additional mechanisms that could potentially alter the performance of the cardiac allograft are ischaemia during harvesting and transport of the donor heart, ${ }^{28-30}$ acute allograft rejections, insidious chronic rejection, ${ }^{4-611}$ denervation of the donor heart, specific fibrosis caused by cyclosporin, ${ }^{151135}$ and possible recurrence of original disease in the recipient.

\section{EVALUATION OF ALTERED DIASTOLIC FUNCTION AFTER CARDIAC TRANSPLANTATION}

While systolic function, as assessed by afterload increment, and the contractile reserve of the cardiac allograft were almost normal, ${ }^{12}$ diastolic function was abnormal. Our data showed an increase in myocardial stiffness, a small but insignificant increase in left ventricular chamber stiffness, and a slight reduction of cycle efficiency after cardiac transplantation (figs 2 and 3 ).

Diastolic function was almost normal after heart and lung transplantation (figs 2 and 3); left ventricular chamber stiffness and myocardial stiffness were increased in only one heart-lung transplant patient. This could be the result of differences in

Table 6 Left ventricular chamber stiffness and myocardial stiffness after cardiac and combined heart-lung transplantation $($ mean $(S D))$

\begin{tabular}{|c|c|c|c|c|c|c|c|}
\hline & \multicolumn{4}{|c|}{ Chamber stiffness } & \multicolumn{3}{|c|}{ Myocardial stiffness } \\
\hline & $a_{c}$ & $b_{c}$ & $v_{c}$ & $L 1$ & $a_{M}$ & $b_{M}$ & $v_{M}$ \\
\hline Total group & $\begin{array}{c}0.020 \\
(0.043)\end{array}$ & $\begin{array}{c}1.12 \\
(0.92)\end{array}$ & $\begin{array}{c}0.03 \\
(0.11)\end{array}$ & $\begin{array}{l}14 \cdot 2 \\
(3 \cdot 57)\end{array}$ & $\begin{array}{c}0.41^{\star} \\
(1.05)\end{array}$ & $\begin{array}{c}21 \cdot 2^{+} \\
(12.5)\end{array}$ & $\begin{array}{c}0.62 \\
(1.03)\end{array}$ \\
\hline Cardiac transplants & $\begin{array}{c}0.022 \\
(0.031)\end{array}$ & $\begin{array}{l}1.22 \\
(0.84)\end{array}$ & $\begin{array}{c}0.02 \\
(0.11)\end{array}$ & $\begin{array}{l}14 \cdot 5 \\
(4 \cdot 21)\end{array}$ & $\begin{array}{l}0.29 \star \star \\
(0.93)\end{array}$ & $\begin{array}{c}22 \cdot 1^{++} \\
(11 \cdot 3)\end{array}$ & $\begin{array}{c}0.54 \\
(1.04)\end{array}$ \\
\hline Heart-lung transplants & $\begin{array}{c}0.013 \\
(0.021)\end{array}$ & $\begin{array}{c}0.82 \\
(0.73)\end{array}$ & $\begin{array}{c}0.05 \\
(0.12)\end{array}$ & $\begin{array}{l}13 \cdot 2 \\
(2 \cdot 62)\end{array}$ & $\begin{array}{c}0.75 \\
(4 \cdot 32)\end{array}$ & $\begin{array}{c}18.5 \\
(17.8)\end{array}$ & $\begin{array}{c}0.69 \\
(0.79)\end{array}$ \\
\hline Control group & $\begin{array}{c}0.007 \\
(0.098)\end{array}$ & $\begin{array}{c}0.73 \\
(0.36)\end{array}$ & $\begin{array}{c}0.03 \\
(0.12)\end{array}$ & $\begin{array}{l}14 \cdot 2 \\
(3 \cdot 09)\end{array}$ & $\begin{array}{l}1.6 \\
(0.71)\end{array}$ & $\begin{array}{l}11 \cdot 1 \\
(6 \cdot 8)\end{array}$ & $\begin{array}{c}0.85 \\
(2.21)\end{array}$ \\
\hline
\end{tabular}

$a_{c}=$ elastic constant; $b_{c}=$ constant of chamber stiffiness; $v_{c}==$ viscoelastic constant; $L 1=$ reference length for calculation of strain; $a_{M}$. $=$ elastic constant; $b_{M}=$ constant of myocardial stiffiness; $v_{M}=$ viscoelastic constant.

$\star \star p<0.001,{ }^{\star} p<0.002 ;{ }^{++} p<0.01 ;{ }^{+} p<0.02$ compared with control group. 

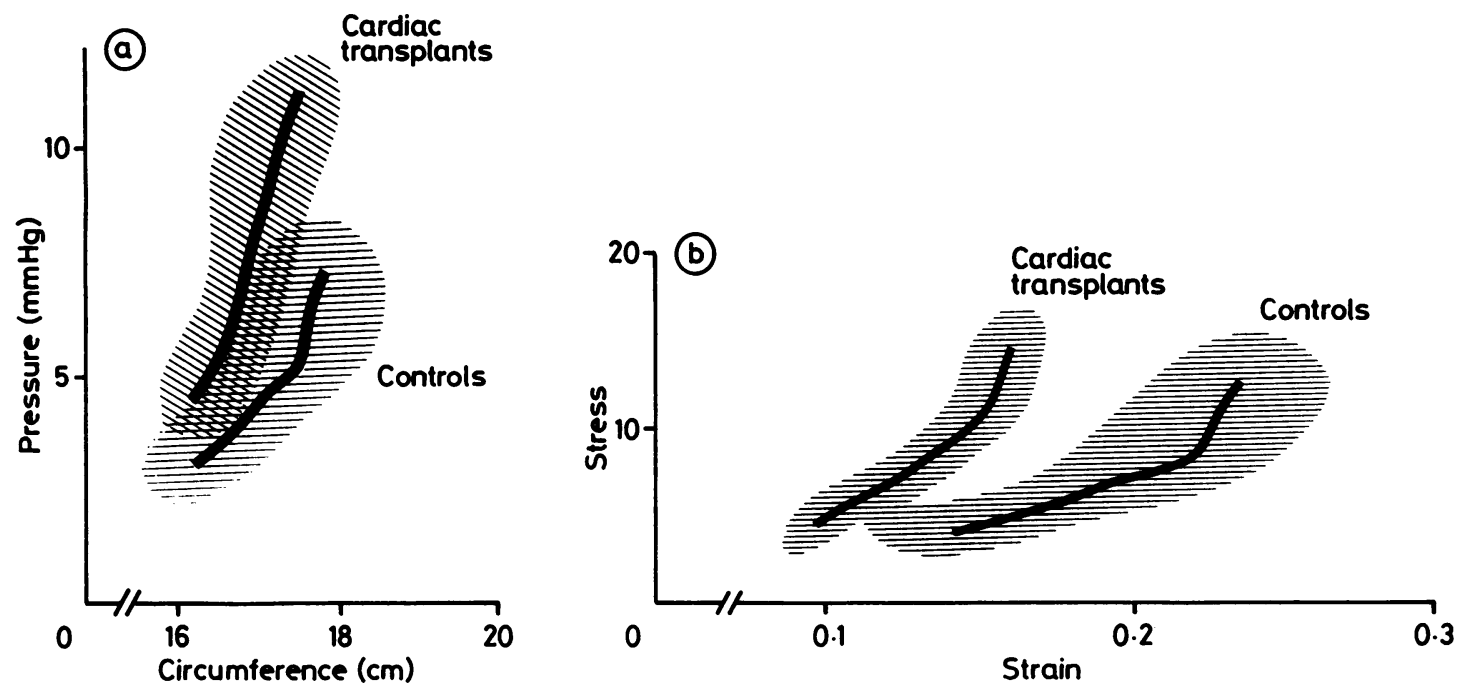

Fig 4 Averaged pressure-circumference (a) and stress-strain (b) relations in controls and after cardiac transplantation. The individual pressure-circumference and stress-strain curves from each patient were divided into 28 discrete points and these were averaged to obtain averaged pressure-circumference and stress-strain curves. The figure shows these averaged pressurecircumference and stress-strain curves with the corresponding standard estimate of the mean. The averaged pressurecircumference and stress-strain curves of the heart-lung transplant patients were no different from those for the control group (data not shown).

myocardial protection: in cardiac transplantation crystalloid cardioplegia was performed but for heartlung transplantation the donor was cooled and blood cardioplegia was performed..$^{36}$ Another explanation is the possible immunological protection of the heart by the lungs.

Others have questioned whether the passive diastolic properties of the myocardium are best represented by a viscoelastic model, ${ }^{37}$ but these theoretical considerations should be of no importance in our study because we saw no differences in the viscoelastic constant between any of the groups. The method reported by Hess et al was used to evaluate passive diastolic filling, because this method correlated well with the extent of endomyocardial fibrosis ${ }^{27}$ Although no attempt was made to measure the extent of myocardial fibrosis in this study, these findings ${ }^{27}$ suggest that increased myocardial stiffness reflects increased myocardial fibrosis. Other explanations such as incomplete relaxation ${ }^{23}$ or considerable asynchrony of the onset of relaxation ${ }^{16}$ could be excluded in our study, because both the time constant of isovolumic pressure decay and the index of left ventricular asynchrony were normal (fig 2).

Finally, steeper pressure-circumference and stress-strain curves could theoretically be caused by a leftward shift of these relations, with the left ventricle working on a steeper portion of the diastolic pressure-circumference and stress-strain curves. However, the reference length $\mathrm{L} 1$ was nearly iden- tical in all groups, which rules out any such leftward shift (table 6, fig 4).

While cycle efficiency was reduced after cardiac transplantation (fig 2), indicating incoordinate contraction and relaxation, the index of left ventricular asynchrony was normal. Although the index of left ventricular asynchrony and cycle efficiency are both indicators of incoordination, they reflect different aspects of it. The index of left ventricular asynchrony reflects variability in timing of relaxation onset, while cycle efficiency is independent of timing but dependent on changes in left ventricular pressure and dimension. Cycle efficiency reflects changes in left ventricular shape during the isovolumic contraction and relaxation periods and therefore incoordinate contraction and relaxation. ${ }^{17-19}$ Changes in left ventricular shape are usually also reflected by the "shape index" as originally described by Chen and Gibson. ${ }^{38}$ In this group of patients with transplants the shape index was not analysed, because most left ventricular angiograms showed apical dyskinesia after the intraoperative use of an apical vent (fig 1); thus the shape index would have given unreliable results. ${ }^{39}$ None the less, the reduction in cycle efficiency after transplantation cannot be explained by apical dyskinesia, because apical dyskinesia was seen after cardiac transplantation and heart-lung transplantation whereas cycle efficiency was normal after heartlung transplantation.

The time constant of isovolumic pressure decay 
was normal in transplant patients. Therefore relaxation seems to be normal. This is of particular interest as relaxation is an active phenomenon that is modified by sympathetic innervation. ${ }^{40} 41$ Although it has been suggested that incoordinate relaxation could affect the time constant of isovolumic pressure decay, ${ }^{16}$ it can be shown mathematically that this is not the case (appendix B).

\section{FACTORS PREDISPOSING TO DIASTOLIC DYSFUNCTION AFTER CARDIAC \\ TRANSPLANTATION}

Our data show that passive diastolic properties are significantly related to the ischaemic time of the donor heart, as is the index of left ventricular asynchrony. This finding accords with experimental findings. ${ }^{3031}$ Donor age showed an inverse relation with passive diastolic properties; this could be because of differences in the cause of death and clinical course among younger donors. In contrast with cardiac transplant patients, only one heart-lung transplant patient showed impaired passive diastolic properties (fig 3). This may be because of the different type of myocardial protection used. The donor heart of this particular patient had a relatively long ischaemic time $(2.92 \mathrm{~h})$ and was obtained from a 14 year old girl, while the recipient was a large 17 year old boy.

The indices of incoordinate relaxation correlated weakly with recipient age. Although for cycle efficiency this correlation was obviously the result of the younger age of heart-lung transplant patients (fig 2 ), this was not the case for the index of left ventricular asynchrony (fig 2). More patients are required to determine whether the relation between incoordinate relaxation and recipient age is the result of the recipient's underlying disease or is simply age related.

Diastolic dysfunction was not related to the interval between transplantation and study; this suggests that there was no progressive deterioration of diastolic function with time. No relation was seen between diastolic dysfunction and immunosuppression with cyclosporin. However, only five of the patients did not receive cyclosporin. Diastolic dysfunction seems to be unrelated to denervation, because diastolic function was almost normal after heart-lung transplantation.

The number of preceding rejection episoodes did not appear to influence diastolic function (table 3 ). This could be because rejection episodes in this group of transplanted patients were adequately treated. Evaluation of the effects of acute and chronic rejection, however, is extremely difficult if not impossible, because there is no way to measure exactly the severity or duration of rejection episodes.
This study confirmed the presence of diastolic dysfunction after cardiac transplantation. Impair- $\varsigma$ ment of diastolic function seemed to be the result of increased myocardial stiffness and a mild degree of incoordinate contraction and relaxation. Increased myocardial stiffness is related to the ischaemic time of the donor heart. There is a basic difference in diastolic properties in patients with heart-lung transplants and those with cardiac transplants. This could be the result of differences in organ preservation or harvesting and of immunological factors.

We thank O M Hess (University of Zurich, Switzerland) for his help in establishing the iteration programs and in preparing the paper. We also thank Dr D. G Gibson (Brompton Hospital, London) for his help in preparing this paper.

This study was supported by a grant from the Deutsche Forschungsgemeinschaft.

\section{Appendix A}

Calculation of left ventricular chamber stiffness by an exponential model with a viscoelastic constant according to the method described by Hess et al. ${ }^{27}$ It was calculated from the following equation:

$$
P(t)=a_{c} e b_{c}{ }^{\star} l(t)+v_{c}{ }^{\star} d l(t) / d t
$$

where $P(t)$ is left ventricular pressure; $a_{C}$ is elastic constant; $b_{c}$ is the constant of chamber stiffness; $v_{c}$ is the viscoelastic constant, and $\mathrm{l}(\mathrm{t})$ is the left ventricular circumference.

The constants $a_{c}, b_{c}$, and $v_{c}$ were calculated by use of the formula mentioned above by iteration so that the least squares estimate between the measured and calculated values was minimised.

Calculation of left ventricular myocardial stiffnessFor calculation of left ventricular myocardial stiffness the stress-strain relations were analysed. Meridional wall stress $(\operatorname{Str}(t))$ was calculated as:

$$
\operatorname{Str}(\mathrm{t})=1.35^{\star} \frac{\mathrm{P}(\mathrm{t})^{\star} \mathrm{D}_{\mathrm{i}}(\mathrm{t})}{4^{\star} \mathrm{h}(\mathrm{t})^{\star}\left(1+\mathrm{h}(\mathrm{t}) / \mathrm{D}_{\mathrm{i}}(\mathrm{t})\right)}\left[\mathrm{g} / \mathrm{cm}^{2}\right]
$$

where $\operatorname{Str}(t)$ is meridional wall stress; $P(t)$ is left ventricular pressure; $D_{i}(t)$ is left ventricular internal diameter; and $h(t)$ is left ventricular posterior wall thickness.

For the calculation of strain (strain( $(t))$ a reference length had to be defined. The reference midwall circumferance L1 was (arbitrarily) calculated for a meridional wall stress of $1 \mathrm{~g} / \mathrm{cm}^{2}{ }^{27} \mathrm{~L} 1$ was calculated by iteration of the following equation:

$$
\operatorname{Str}(t)=a^{\star} e^{b \star} 1(t)+v^{\star} d l(t) / d t
$$


Natural strain $(E(t))$ was calculated as:

$$
E(t)=\ln (1(t))-\ln (L 1)
$$

Myocardial stiffness was calculated by iteration of the following equation:

$$
\operatorname{Str}(t)=a_{M}{ }^{\star} e^{b_{M}}{ }^{\star} E(t)+v_{M}{ }^{\star} d E(t) / d t
$$

where $a_{M}$ is the elastic constant; $b_{M}$ the constant of myocardial stiffness; and $v_{M}$ the viscoelastic constant).

\section{Appendix B}

Two segments $A$ and $B$ with identical time constants of relaxation are analysed. Isovolumic pressure decay is assumed to be represented by a monoexponential model with asymptote. If segment $B$ starts to relax the time interval $t^{\star}$ later than segment $A$, isovolumic pressure decay is expressed by:

$$
\begin{aligned}
& \text { Segment A: } P_{A}(t)=a^{\star} e^{b^{\star} t}+c \text {, and } \\
& \text { Segment } B: P_{B}(t)=a^{\star} e^{b^{\star}\left(t+t^{\star}\right)}+c
\end{aligned}
$$

The resulting pressure $P(t)$ from both segments can be expressed by:

$$
\begin{aligned}
2^{\star} P(t) & =P_{A}(t)+P_{B}(t) \\
& =P_{A}(t)+P_{A}\left(t+t^{\star}\right) \\
& \left.=\left[a^{\star} e^{b^{\star} t}+c\right]+\left[a^{\star} e^{b^{\star}\left(t+t^{\star}\right.}+c\right]+c\right] \\
& =\left[a^{\star} e^{b^{\star} t}+a^{\star} e^{b^{\star} t \star} e^{b^{\star} t^{\star}}\right]+2 c \\
& =e^{b^{\star} t \star}\left[a+a^{\star} e^{b^{\star} t^{\star}}\right]+2 c \\
P(t) & =\left[a / 2+a / 2^{\star} e^{b^{\star} t^{\star}}\right] e^{\star} e^{b^{\star} t}+c
\end{aligned}
$$

because $t^{\star}$ is a constant time interval, $e^{b^{\star} t^{\star}}$ is also constant; thus the resulting pressure $P(t)$ can be expressed by:

$$
P(t)=a^{\star \star} e^{b^{\star} t}+c
$$

While the time constant of this relation $T=-1 / b$ remains constant with an asynchronous onset of relaxation, the constant $\mathbf{a}=\mathbf{P}\left(\mathrm{t}_{0}\right)$ changes by the factor:

$$
\left[1 / 2+1 / 2 e^{b^{\star} t t^{\star}}\right]
$$

\section{References}

1 Yacoub MH, Reid CJ, Al-Khadami A, Radley-Smith R. Cardiac transplantation-the London experience. $Z$ Kardiol 1985;74:45-50.

2 Hetzer R, Warnecke H, Schüler S, Steinhoff U, Borst HG. Heart transplantation-a two-year experience. $Z$ Kardiol 1985;74:51-8.

3 Struck E, Meisner H, Sebening F. Heart transplantation: limitations and perspectives. $Z$ Kardiol 1985;74:59-63.

4 Jamieson SW, Oyer PE, Baldin CP, Stinson EB, Shumway NE. Heart transplantation for end-stage ischemic heart disease: the Stanford experience. Heart Transplant 1984;3:224-7.

5 Jamieson SW, Oyer PE, Bieber CP, Stinson EB, Shumway NE. Transplantation for cardiomyopathy: a review of the results. Heart Transplant 1984;2:2832.

6 McGregor CGA, Jamieson SW, Baldwin JC, et al. Combined heart-lung transplantation for end-stage Eisenmenger's syndrome. $J$ Thorac Cardiovasc Surg 1986;91:443-50.

7 Campeau L, Pospisil L, Grondin P, Dyrda I, Lepage G. Cardiac catheterization findings at rest and after exercise in patients following cardiac transplantation. Am J Cardiol 1970;25:523-8.

8 McLaughlin PR, Kleiman JH, Martin RP, et al. The effect of exercise and atrial pacing on left ventricular volume and contractility in patients with innervated and denervated hearts. Circulation 1978;58:476-83.

9 Pope SE, Stinson EB, Daughters GT, Schroeder JS, Ingels NB, Alderman EL. Exercise response of the denervated heart in long-term cardiac transplant recipients. Am J Cardiol 1980;46:213-8.

10 Banner NR, Lloyd MH, Hamilton RD, Innes JA, Guz A, Yacoub MH. Cardiopulmonary response to dynamic exercise after heart and combined heart-lung transplantation. Br Heart J 1989;61:215-23.

11 Dawkins KD, Jamieson SW, Hunt SA, et al. Long-term results, hemodynamics, and complications after combined heart and lung transplantation. Circulation 1985;71:919-26.

12 Borow KM, Neumann A, Ahrensman FW, Yacoub MH. Left ventricular contractility and contractile reserve in humans after cardiac transplantation. Circulation 1985;71:866-72.

13 Dawkins KD, Oldershaw PJ, Billingham ME, et al. Changes in left ventricular diastolic function as a noninvasive marker of cardiac allograft rejection. Heart Transplant 1984;3:286-94.

14 Leachman RD, Cokkinos DVP, Rochelle DG, et al. Serial hemodynamic study of the transplanted heart and correlation with rejection. $J$ Thorac Cardiovasc Surg 1979;61:561-9.

15 Greenberg ML, Uretsky BF, Reddy S, et al. Long-term hemodynamic follow-up of cardiac transplant patients treated with cyclosporine and prednisone. Circulation 1985;71:487-94.

16 Takeuchi M, Fujitani K, Kurogane K, et al. Effects of left ventricular asynchrony on time constant and extrapolated pressure of left ventricular pressure decay in coronary artery disease. $\mathrm{J} \mathrm{Am} \mathrm{Coll} \mathrm{Cardiol}$ 1985;6:597-602.

17 Gibson DG, Brown DJ. Assessment of left ventricular systolic function in man from simultaneous echocardiographic and pressure measurements. $\mathrm{Br}$ Heart $J$ 1976;38:8-17.

18 Upton MT, Gibson DG. The study of left ventricular function from digitized echocardiograms. Prog Cardiovasc Dis 1978;20:359-84.

19 Hausdorf G, Gravinghoff L, Keck EW. Incoordinate contraction and relaxation in d-transposition of the great arteries with intact ventricular septum. Basic Res Cardiol 1986;81:134-41. 
20 Weisfeldt ML, Frederiksen JW, Yin FCP, Weiss JL. Evidence of incomplete left ventricular relaxation in the dog. J Clin Invest 1978;62:1296-302.

21 Thompson DS, Waldron CB, Juul SM, et al. Analysis of left ventricular pressure during isovolumic relaxation in coronary artery disease. Circulation 1982; 65:690-7.

22 Thompson DS, Waldron CB, Coltart DJ, Jenkins BS, Webb-Peploe MM. Estimation of time constant of left ventricular relaxation. Br Heart J 1983;49:250-8.

23 Pasipoularides A, Mirsky I, Hess OM, Grimm J, Krayenbuehl HP. Myocardial relaxation and passive diastolic properties in man. Circulation 1986;74: 991-1001.

24 Rankin JS, Arentzen CE, McHale PA, Ling D, Anderson RW. Viscoelastic properties of the diastolic left ventricle in the conscious dog. Circ Res 1977;41: 37-45.

25 Hess OM, Grimm J, Krayenbuehl HP. Diastolic simple elastic and viscoelastic properties of the human left ventricle in man. Circulation 1979;59:1178-87.

26 Hess OM, Schneider J, Koch R, Bamert C, Grimm J, Krayenbuehl HP. Diastolic function and myocardial structure in patients with myocardial hypertrophy. Special reference to normalized viscoelastic data. Circulation 1981;63:360-71.

27 Hess OM, Ritter M, Schneider J, Grimm J, Turina M, Krayenbuehl HP. Diastolic stiffness and myocardial structure in aortic valve disease before and after valve replacement. Circulation 1984;69:855-65.

28 Emery RW, Cork RC, Levinson MM, et al. The cardiac donor: a six year experience. Ann Thorac Surg 1986;41:356-62.

29 Burt JM, Copeland JG. Myocardial function after preservation for 24 hours. $J$ Thorac Cardiovasc Surg 1986;92:238-46.

30 Wicomb WN, Cooper DKC, Lanza RP, Novitzky D, Isaacs $S$. The effects of brain death and 24 hours storage by hypothermic perfusion on donor heart function in the pig. $J$ Thorac Cardiovasc Surg 1986;91:896-909.

31 Emery RW, Cork R, Christensen R, et al. Cardiac transplant patient at one year. Cyclesporine vs conventional immunosuppression. Chest 1986;90:29-33.

32 Frazier OH, Cooley DA, Painvin GA, Chandler LB, Okereke OU. Cardiac transplantation at the Texas Heart Institute: comparative analysis of two groups of patients (1968-1969 and 1982-1983). Ann Thorac Surg 1985;39:303-7.

33 Yacoub MH, Alivizatos P, Khagani A. Mitchell A. The use of cyclosporine, azathioprine, and antithymocyte globulin with or without low-dose steroids for immunosuppression of cardiac transplant patients. Transplant Proc 1985;17:221-2.

34 Billingham ME. Diagnosis of cardiac rejection by endomyocardial biopsy. Heart Transplant 1980;1: 25-30.

35 Griffith BP, Hardesty RL, Bahnson HT, Bernstein RL, Starzl TE. Cardiac transplants with cyclosporine A and low-dose prednisone: histologic graduation of rejection. Transplant Proc 1983;15:1241-3.

36 Yacoub $\mathbf{M H}$, Khaghani A, Banner N, Tajkarimi S, Fitzgerald M. Distant organ procurement for heart and lung transplantation. Transplant Proc 1989; 21:2548-50.

37 Pouleur H, Karlinger JS, LeWinter MM, Covell JW. Diastolic properties of the intact canine left ventricle. Circ Res 1979;45:410-9.

38 Chen W, Gibson DG. The relation of isovolumic relaxation to left ventricular wall motion in man. Br Heart J 1979;42:51-6.

39 Hausdorf G, Grävinghoff L, Keck EW. Effects of persisting myocardial sinusoids on left ventricular performance in pulmonary atresia with intact ventricular septum. Eur Heart J 1987;8:291-6.

40 Grossmann W, McLaurin LP. Diastolic properties of the left ventricle. Ann Intern Med 1976;84:316-26.

41 Morad M, Rolett EL. Relaxing effects of catecholamines on mammalian heart. $J$ Physiol (Lond) 1972;224:537-58. 